\title{
Seismic Analysis of Hybrid System Bridge of Multi-Span Continuous Girder and Arches
}

\author{
Kuihua $\mathrm{Mei}^{1}$, Wangwang $\mathrm{Fu}^{1}$, Jufeng $\mathrm{Su}^{1}$ \\ ${ }^{1}$ School of Highway, Chang'an University, Xi'an 710064, China
}

\begin{abstract}
The Chengdong Hanjiang Bridge in Ankang City is a multi-span continuous beam-arch combination system bridge of $(75+2 \times 125+160+2 \times 125+75) \mathrm{m}$, and its site is located in the earthquake zone. Calculation model based on Midas / Civil finite element software process analysis method is applied to seismic response analysis using power. At the same time, in order to influence the travelling wave effect and the seismic isolation system on the internal force of the bridge structure, corresponding finite element models were established and calculated with time history analysis. The finite element model under non-uniform excitation uses the "Large Mass Method" (LMM) for analysis and calculation under different wave velocity multi-point excitations. The results show that after considering the traveling wave effect, the displacement and bending moment of the control section of each hole increase, and the internal force of the fixed pier increases. When the wave velocity is $600 \mathrm{~m} / \mathrm{s}$, the traveling wave effect strengthens the seismic response of the structure the most. With the increase of the wave velocity, the seismic response of the structure gradually approaches the seismic response under uniform excitation. After the friction pendulum seismic isolation support is used, it is fixed. The bending moment of Pier No. 32 has been reduced by $80 \%$, the stiffness of the whole bridge is more balanced, the forces of each pier are relatively close, and the isolation effect is good.
\end{abstract}

\section{Preface}

The energy released by the source during an earthquake is transmitted to the surface in the form of waves. For longspan bridge structures, there is a certain phase difference when the seismic wave reaches each point of the structural foundation, which is called the "Traveling Wave Effect". At present, bridge structures have Ductile Seismic systems and Seismic Isolation systems. The ductile seismic system relies on plastic hinges formed on the pier to dissipate energy, and the support connection device needs to maintain elasticity; The seismic isolation system relies on the seismic isolation devices at the upper and lower joints to dissipate energy, and the pier body remains elastic. Therefore, the vibration isolation device can avoid the unavoidable structural damage of the bridge pier structure after the plastic deformation in the ductile seismic system. At the same time, the deformation performance of the vibration isolation device can be ensured through appropriate parameter selection and design, which can ensure the reliable transmission of the connecting parts. For force and support, it can also avoid serious damage to the main structure.

At present, many scholars have done corresponding research on the seismic response of large-span bridge structures in China, and have achieved certain results. Tong Shen-jia conducted a seismic isolation study on a single-span down-thickness concrete-filled steel tube arch bridge with a span of $99 \mathrm{~m}[1]$, and compared and analysed the internal forces of the structure under uniform excitation and multi-point excitation.

Hu Zhi-ming, Li Jing-li et al. Carried out research on non-uniform excitation conditions of single-span downthrough concrete-filled steel tubular arch bridges in the form of inclined arches and inclined booms[2]. Jia Yi et al. Studied the seismic performance of multi-span long continuous bridges with different seismic system. Shang Wei-bo and Zhao Guo-wang studied the seismic system of porous continuous beam bridges under longitudinal earthquakes. Existing research results are mostly for single-span arch bridges or continuous beam bridges, but rarely for large-span porous beam-arch composite arch bridges.

The bridge site of the Cheng dong Han jiang River Bridge in An kang City is located in the earthquake zone. In order to study the internal force response of the structure under earthquake, based on the Midas / Civil finite element software, the seismic analysis of the bridge structure is performed using dynamic time history analysis. The structure is subjected to seismic analysis considering travelling wave effects, and the structure response when the structure adopts a vibration isolation system is also analysed.

\section{Project overview}

Ankang Chengdong Hanjiang Bridge $(75+2 \times 125+160$ $+2 \times 125+75 \mathrm{~m}$ ) is a seven-hole continuous beam-arch composite system bridge. The overall arrangement is

\footnotetext{
*Corresponding author: 1964479363@qq.com
} 
shown in Fig 1. A three-dimensional finite element model was established using Midas/civil finite element software. In order to consider the influence of approach bridges, a continuous beam model of adjacent approach bridges was established. The suspender of the main bridge is simulated by a truss unit, the bearing of the approach bridge is a basin bearing, and the linear connection unit is used for simulation. The finite element model is shown in Fig 2.

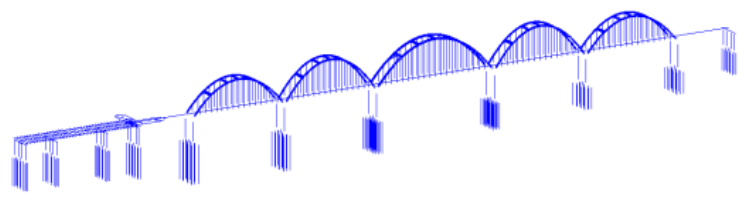

Fig. 2. Finite element model

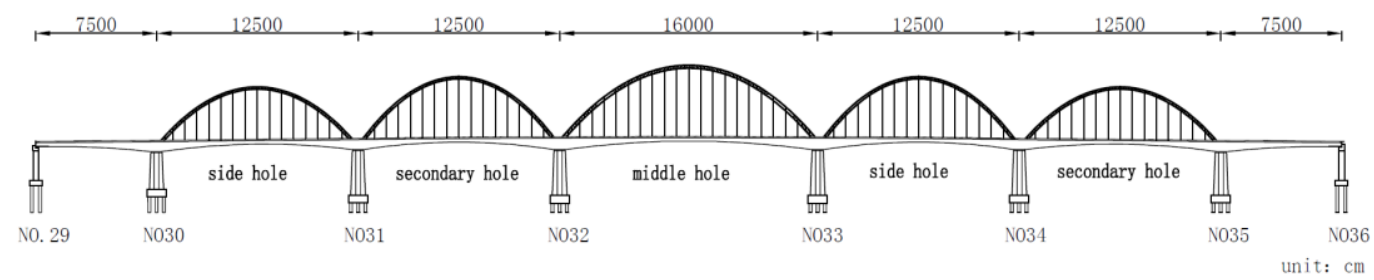

Fig. 1. General layout of the main bridge

\section{Earthquake input}

The main bridge has a maximum span of $160 \mathrm{~m}$ and is a Class A bridge. According to Article 5.1.3 of the Highway Bridge Seismic Design Rules (JTG/T B02-01-2008), Class A bridges should be determined in accordance with a special earthquake engineering site seismic safety evaluation .According to The Work Safety Report of Chengdong Hanjiang River Bridge in Ankang City, the site of the bridge is a Class II site, and the basic earthquake intensity is VII. The peak acceleration of the design basic earthquake is $0.104 g$ and the characteristic period is $0.47 \mathrm{~s}$.

In this paper, three seismic waves with a probability of exceeding $2 \%$ in the 50 -year safety assessment report are used as the seismic input at the E2 level. The seismic acceleration time-history curve of the three seismic waves is shown in Figure 3. The vertical + vertical ground motion input method is adopted. The vertical earthquake action takes $2 / 3$ of the horizontal earthquake action. The calculation results take the maximum of the three timehistory wave calculation results.

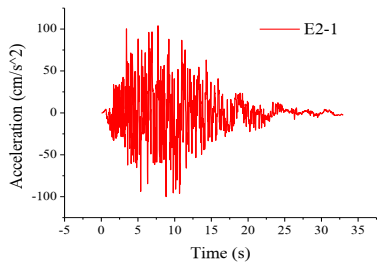

Fig. 3-1. Time history function curve 1

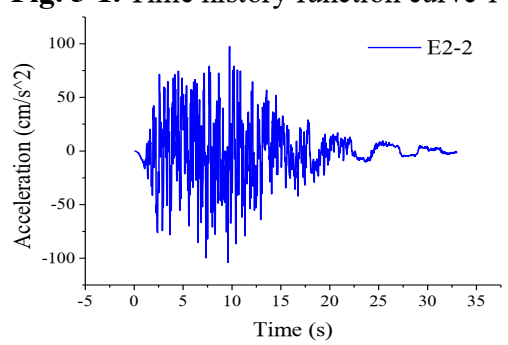

Fig. 3-2. Time history function curve 2

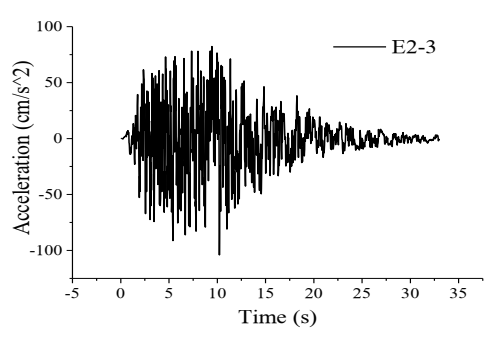

Fig. 3-3. Time history function curve 3

\section{Traveling wave effect}

\subsection{Establishment of structural equations of motion under non-uniform excitation}

The multi-point excitation motion equation of a long-span bridge considering the traveling wave effect can be expressed as (subscript $b$ indicates a structural support node, and subscript $s$ indicates a non-support node other than a support node):

$$
\begin{aligned}
& {\left[\begin{array}{ll}
\mathbf{M}_{\mathbf{s s}} & \mathbf{M}_{\mathbf{s b}} \\
\mathbf{M}_{\mathbf{b s}} & \mathbf{M}_{\mathbf{b b}}
\end{array}\right]\left\{\begin{array}{l}
\ddot{u}_{s} \\
\ddot{u_{b}}
\end{array}\right\}+\left[\begin{array}{ll}
\mathbf{C}_{\mathrm{ss}} & \mathbf{C}_{\mathbf{s b}} \\
\mathbf{C}_{\mathbf{b s}} & \mathbf{C}_{\mathbf{b b}}
\end{array}\right]\left\{\begin{array}{l}
\dot{u}_{s} \\
\dot{u}_{b}
\end{array}\right\}} \\
& +\left[\begin{array}{ll}
\mathbf{K}_{\mathbf{s s}} & \mathbf{K}_{\mathbf{s b}} \\
\mathbf{K}_{\mathrm{bs}} & \mathbf{K}_{\mathbf{b b}}
\end{array}\right]\left\{\begin{array}{l}
u_{s} \\
u_{b}
\end{array}\right\}=\left\{\begin{array}{c}
\mathbf{0} \\
\mathbf{P}_{\mathbf{b}}
\end{array}\right\}
\end{aligned}
$$

In the formula, $\ddot{u}_{b}, \dot{u}_{b}, u_{b}$ are the absolute acceleration, velocity, and forced displacement of the supporting nodes; $\ddot{u}_{s}, \dot{u}_{s}, u_{s}$ are the absolute acceleration, velocity, and forced displacement of the non-supported nodes, respectively. $\mathbf{P}_{\mathbf{b}}$ is the total external force acting on the support node during the earthquake; $\mathbf{C}$ is the damping, $\mathbf{K}$ is the stiffness, and $\mathbf{M}$ is the mass.

In this paper, the response of the structure is calculated with large-mass method. A concentrated mass that is much greater than the structural mass is added to the supporting nodes of the structure, and the degrees of freedom along the seismic input direction at the supporting nodes are released. A force is then applied to the support nodes in the direction of the earthquake to 
simulate earthquake action. Therefore, the structural motion equation of the mass method is:

$$
\left\{\begin{array}{l}
\mathbf{M}_{s s} \dot{u}_{s}+\mathbf{M}_{s b} \ddot{u}_{b}+\mathbf{C}_{s s} \dot{u}_{s}+\mathbf{C}_{s b} \dot{u}_{b}+\mathbf{K}_{s s} \dot{u}_{s}+\mathbf{K}_{s b} \dot{u}_{b}=0 \\
\mathbf{M}_{\mathrm{bs}} \dot{u}_{s}+\mathbf{M}_{b b} \ddot{u}_{b}+\mathbf{C}_{b s} \dot{u}_{s}+\mathbf{C}_{b b} \dot{u}_{b}+\mathbf{K}_{b s} \dot{u}_{s}+\mathbf{K}_{b b} \dot{u}_{b}=\mathbf{M}_{b b} \ddot{\mathbf{u}}_{\mathrm{g}}
\end{array}\right.
$$

Divide both sides of the second equation of the above equation by $\mathbf{M}_{b b}$ (concentrated large mass). Since $\mathbf{M}_{b b}$ is much larger than other parameters, $\ddot{\mathbf{u}}_{b} \approx \ddot{\mathbf{u}}_{g}$ can be obtained. Deducible:

$$
\mathbf{M}_{s s} \ddot{\mathbf{u}_{s}}+\mathbf{C}_{s s} \dot{\mathbf{u}_{s}}+\mathbf{K}_{s s} \mathbf{u}_{s}=-\mathbf{C}_{s b} \dot{\mathbf{u}}_{g}-\mathbf{K}_{s b} \mathbf{u}_{g}
$$

Then the above equation is a motion equilibrium equation solved by the mass method under multi-point excitation.

\subsection{The seismic response results considering travelling wave effects}

Three time-history waves are input along the bridge direction, and the maximum value of three sets of timehistory seismic responses is taken. Assume that seismic waves propagate from left to right in the longitudinal direction, and the wave speeds are different, and the time to reach the pier supports is also different. When inputting ground motions, seven operating conditions with wave speeds of $600 \mathrm{~m} / \mathrm{s}, 800 \mathrm{~m} / \mathrm{s}, 1000 \mathrm{~m} / \mathrm{s}, 1200 \mathrm{~m} / \mathrm{s}, 1400 \mathrm{~m} / \mathrm{s}$, $2000 \mathrm{~m} / \mathrm{s}$ and consistent excitation are considered. Because the structure is basically symmetrical, take the middle section of the middle hole arch ribs, the middle section of the side holes arch ribs, the middle section of the secondary side holes arch ribs, the mid-span section of main beam and the arch foot sections as crucial sections. The calculation of the crucial sections under various load condition is taken. A comparative analysis is performed based on the seismic response of the structure under the action of a uniformly excited earthquake to calculate the effect of the traveling wave effect on the internal force and displacement of the continuous beam-arch composite structure. Fig 5-8 is the relative change rate of the displacement of the crucial sections under different conditions based on consistent excitation; Fig 4 is the relative change of bending moment of the main beam midsection rate.

Table 1. Internal force of the bottom of the pier

\begin{tabular}{cccc}
\hline $\begin{array}{c}\text { Wave } \\
\text { velocity } \\
(\mathrm{m} / \mathrm{s})\end{array}$ & $\begin{array}{c}\text { Axial } \\
\text { force } \\
(\mathrm{kN})\end{array}$ & $\begin{array}{c}\text { Shear force } \\
(\mathrm{kN})\end{array}$ & $\begin{array}{c}\text { Bending } \\
\text { moments } \\
(\mathrm{kN} . \mathrm{m})\end{array}$ \\
\hline 600 & 123936 & 51044 & 925286 \\
800 & 120478 & 47355 & 881787 \\
1000 & 115628 & 44725 & 851027 \\
1200 & 108273 & 43326 & 824850 \\
1400 & 105633 & 41147 & 803333 \\
2000 & 104158 & 39548 & 785856 \\
\hline Consistent & 103117 & 39195 & 776768 \\
incentive & & & \\
\hline
\end{tabular}

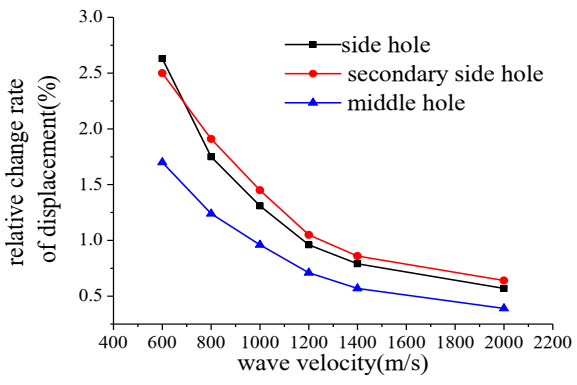

Fig. 4. Relative change rate of displacement of mid-span section of main beam

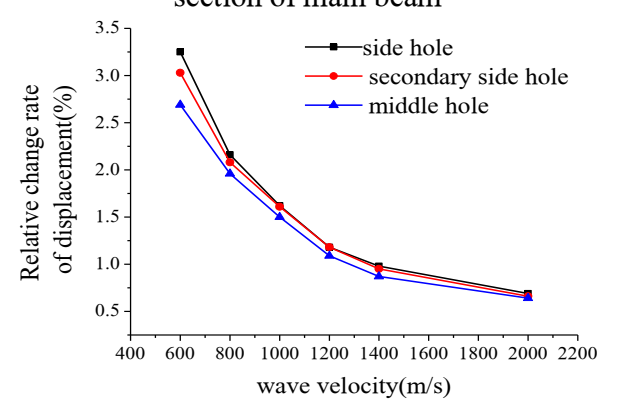

Fig. 5. Relative change rate of displacement of arch foot

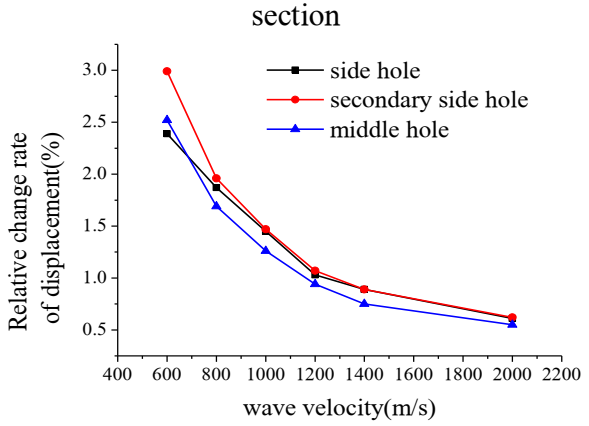

Fig. 6. Relative change rate of displacement of mid-span section of arch rib

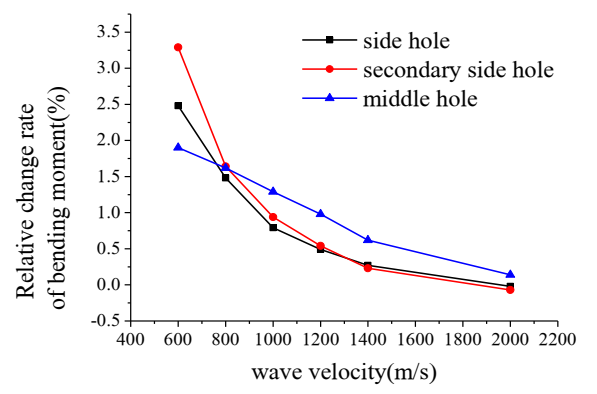

Fig. 7. Relative change rate of bending moment of mid-span section of main beam

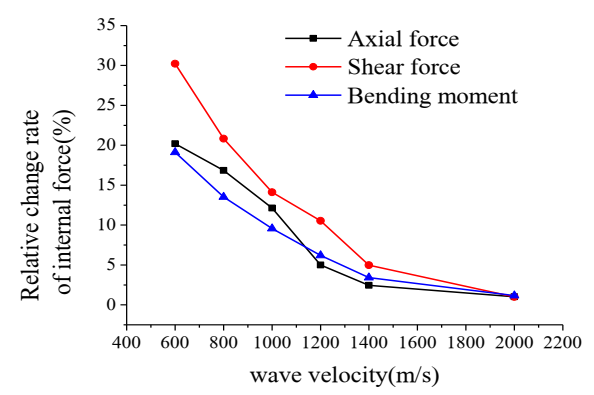

Fig. 8. Relative change rate of internal force of $32 \#$ bridge pier bottom section

According to the Fig 4-7, The displacements and the bending moment of the crucial sections are maximum when the wave velocity is $600 \mathrm{~m} / \mathrm{s}$. The maximum 
displacement of the arch foot section, the mid-span section of main beam occurs in the side hole. Compared with the result of the uniform excitation, the displacement increased by $2.63 \%$ and $3.25 \%$, respectively. The maximum displacement of the middle section of the arch rib occurs in the secondary side hole, which increased by $3.00 \%$ compared with the displacement under the uniform excitation condition. The maximum displacement of the mid-span moment of the main beam span occurs at the secondary hole. And as the wave velocity increases, the displacements and bending moments of each section gradually decrease and approach to the displacements and bending moments under uniform excitation conditions. Therefore, compared to the uniform excitation, the increase of displacement and bending moment of crucial sections is small. And as the wave velocity increases, the increase gradually decreases, and finally approaches the structural response under uniform excitation.

For the calculation of the sbstructure of the bridge, because the traveling wave effect has no effect on the extreme response of the movable pier, only the extreme response of the fixed pier No.32 bridge pier under various conditions is analyzed. The seismic response of No.32 pier is shown in Fig 8 and Table 1. The data in the table is the maximum value of pier section under three sets of time history waves in each load condition.

According to Table 1 and Fig 8, it can be clearly seen that the effect of the traveling wave effect on the internal force of the No.32 bridge pier is significant. The maximum increase of internal force occurs when the wave velocity is $600 \mathrm{~m} / \mathrm{s}$, of which the maximum increase of axial force is $20.19 \%$, the maximum increase of shear force is $30.23 \%$, and the maximum increase of bending moment is $19.12 \%$. The larger the wave velocity, the closer the extreme value response under non-uniform excitation is to the extreme value response of the structure under uniform excitation, but as the wave velocity increases, the increase in internal force gradually decreases.

\section{The seismic isolation system}

\subsection{Friction Pendulum System}

For earthquake action, the traditional structural design concept is to make the structure capable of resisting earthquake action. The seismic isolation support can extend the basic period of the structure, effectively dissipate the energy generated by the earthquake, and reduce the seismic response of the structure. The Friction Pendulum System is widely used because of its low sensitivity to the frequency range of seismic excitation and high stability of seismic performance. Its structure is shown in Fig 9.

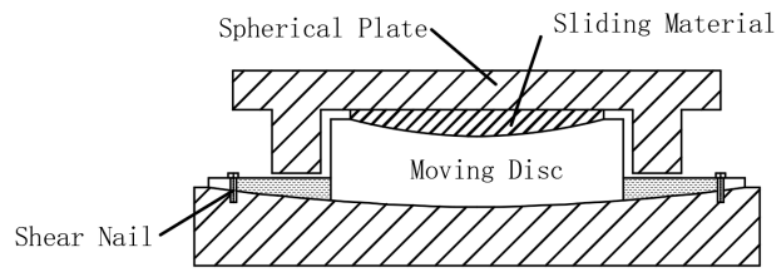

Fig. 9. Schematic diagram of the structure of the Friction Pendulum Bearing

\subsection{Seismic isolation scheme}

When the main bridge structure is not designed for seismic isolation, fixed supports are adopted at the pier of No.32, and the other pier are sliding bearings. Therefore, the seismic response of the main bridge in the direction of the bridge is all borne by the No.32 pier, which causes the bottom moment of the pier of the No.32 pier to be too large, while the other pier does not fully exert its bearing capacity. Therefore, the main bridge structure is designed for vibration reduction and isolation, and the whole bridge adopts FPS.

From the shear force-deformation relationship of the friction pendulum-isolated support, it can be known that the friction coefficient and equivalent sliding radius are the main parameters that affect the isolation effect of the FPS. In this paper, the friction coefficient $\mu$ is all taken as 0.03 . In order to select a suitable FPS support, the seismic response of the main bridge when the curvature slip radius is $2,3,4,5 \mathrm{~m}$ is calculated. Fig 10-11 shows the maximum value of the bottom moment of the main bridge pier and the maximum displacement of the FPS support under different curvature radii.

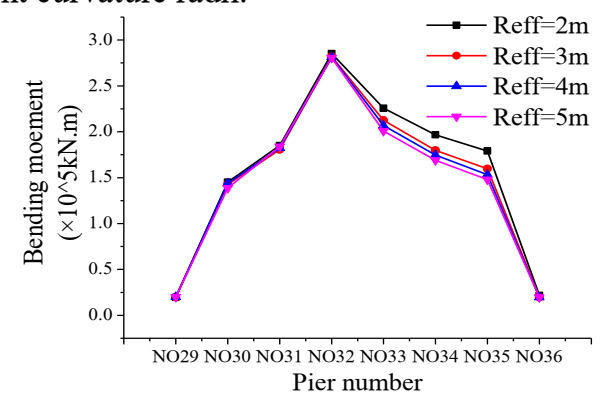

Fig. 10. Max. Moment of the pier footings under different equivalent sliding radii

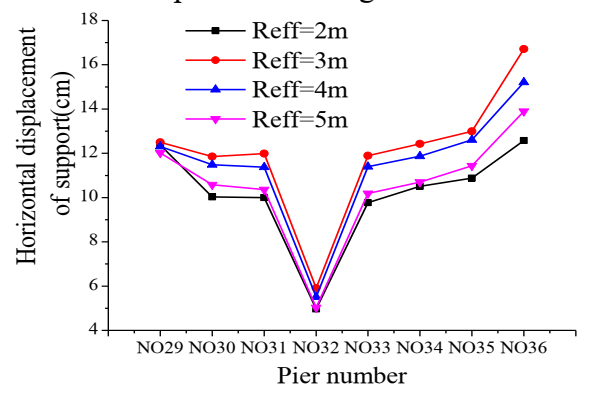

Fig. 11. Max. displacement of Friction Pendulum 


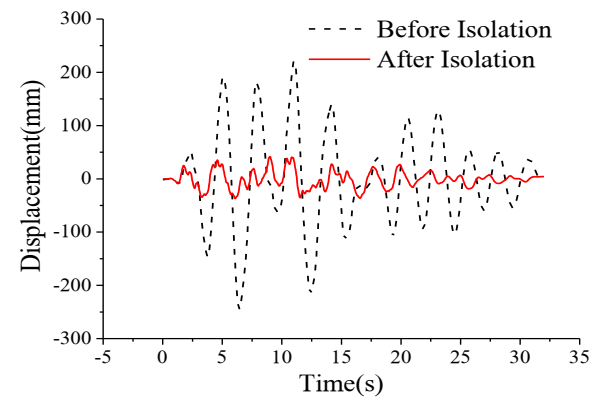

Fig. 12. Time-history Curve of Moment at the bottom of Pier No. 32 bearing at different equivalent sliding radii

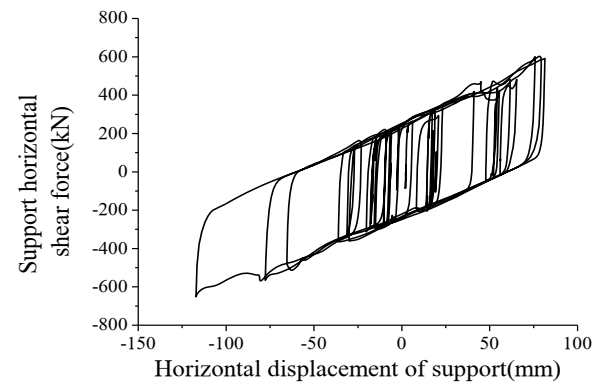

Fig. 13. Hysteretic Curves of Friction Pendulum Bearing at Pier No.32

It can be seen from Fig 10 that with the increase of the equivalent sliding radius, the bending moments of the pier bottoms of the No.29 and No.36 bridge piers decreases in different degrees. It can be seen from Fig 11 that when Reff $=3 \mathrm{~m}$, the displacement of each support is the largest, that is, Reff $=3 \mathrm{~m}$ is a critical value. When the curvature radius of the support is greater than $3 \mathrm{~m}$, the displacement of each support decreases under uniform excitation. Therefore, when the equivalent sliding radius changes from 2 to $5 \mathrm{~m}$, the bending moment at the bottom of the pier does not change much, and the bearing displacement begins to decrease after reaching the critical point. Therefore, in this paper, the equivalent sliding radius of the FPS support is $2 \mathrm{~m}$, and the friction coefficient is 0.03 .

\subsection{Seismic response of the isolation scheme}

Taking Reff $=2 \mathrm{~m}$ and friction coefficient as 0.03 , the response of the bridge structure under the earthquake was calculated, and the maximum bending moment of the pier bottom without isolation and using the isolation system was compared and analyzed. The calculation results are shown in Table 2.

Table 2. Max. Values of Moment of Pier Footings

\begin{tabular}{cccc}
\hline \multirow{2}{*}{$\begin{array}{c}\text { Pier } \\
\text { number }\end{array}$} & \multicolumn{2}{c}{ Bending Moment(kN.m) } & Isolation \\
\cline { 2 - 3 } & $\begin{array}{c}\text { Before } \\
\text { isolation }\end{array}$ & $\begin{array}{c}\text { After } \\
\text { isolation }\end{array}$ & rate (\%) \\
\hline NO29 & 27963.22 & 19644.33 & 29.75 \\
NO 30 & 113326.73 & 145139.83 & -28.07 \\
NO 31 & 178476.63 & 185106.46 & -3.71 \\
NO 32 & 1439706.84 & 285359.46 & 80.18 \\
NO 33 & 181305.53 & 225717.76 & -24.50 \\
NO 34 & 185646.54 & 196609.89 & -5.91 \\
NO 35 & 166987.01 & 179049.95 & -7.22 \\
NO 36 & 32670.41 & 21707.75 & 33.56 \\
\hline
\end{tabular}

It can be seen from Table 2 that after the FPS support is set, the bending moment at the bottom of Pier No.32 of the bridge piers is reduced by $80.18 \%$ under earthquake action along the bridge, The bending moments at the bottom of other piers have increased in different amplitudes. Therefore, after the FPS bearings are set, the forces of each pier are more balanced, which greatly reduces the internal force of the fixed pier. It can be seen from Fig. 13 that under the earthquake action along the bridge, the hysteresis curve shape of the FPS support in the direction along the bridge is regular, the envelope area is large, and the energy consumption effect is good.

\section{Conclusions}

Based on the dynamic time history analysis of the Chengdong Hanjiang River Bridge in Ankang City, considering the effect of the traveling wave effect on the seismic response of the structure, and designing the main bridge for seismic isolation, the following conclusions can be drawn:

(1) After considering the traveling wave effect, as the wave velocity increases, the displacement and bending moment at the control section of the structure increase, but the greater the wave velocity, the smaller the increase; the internal force of the substructure's fixed pier bottom section increases significantly, but The increase rate decreases as the wave speed increases;

(2) Under the action of non-uniformly excited earthquakes, the traveling wave effect has the largest influence on the seismic response of the structure at a wave velocity of $600 \mathrm{~m} / \mathrm{s}$. But as the wave velocity increases, the amplitude of its change will decrease, and the closer the seismic response of the structure is to the seismic response of the structure under uniform excitation. Therefore, in the calculation of the seismic response of the actual project, the structural response under the multipoint excitation of lower wave speed should be taken as the reference;

(3) In the ductile seismic system, the seismic response of the structure under the earthquake along the bridge is mainly borne by the fixed No.32 pier. Due to the large mass of the superstructure of the main bridge, the stress on the No.32 pier is extremely unfavorable, so the ordinary continuous beam system is not good for the seismic safety of bridge;

(4) After the FPS support is installed, the bending moment at the bottom of Pier No.32 can be greatly reduced, the stiffness of the bridge tends to be balanced, and the forces of each Pier are relatively close, which can greatly reduce the seismic response of the structure. Therefore, for long-span porous continuous beam-arch composite bridges, a seismic isolation system is recommended.

\section{References}

1. J. S. Tong, X. Wu, G. Li, Bridge Construction, 2,2730(2008)

2. Z. M. Hu, J. Y. Li, Y. T. Huang, Bridge Construction, 1,25-28(2010) 
3. K. H. Mei, X. L. Wang, Bridge Construction, 47,4,48-53(2017)

4. X. H. He, Y. B. Ge, Bridge Construction, 47,1,7681(2017)
5. C. Y. Zhang, L. S. Zhou, World Bridge, 46, 6, 41-45 (2018)

6. Y. Li, S. Wang, Y. Y. Che, Journal of Vibration and Shock,34,10,1-5(2015) 